\section{JOURNAL OF PLANT PHYSIOLOGY}

www.elsevier.de/jplph

\title{
Gene expression analysis of germinating rice seeds responding to high hydrostatic pressure
}

\author{
Xuncheng Liu ${ }^{\mathrm{a}, \mathrm{b}, 1}$, Mei Zhang ${ }^{\mathrm{a}, 1}$, Jun Duan ${ }^{\mathrm{a}, *}$, Keqiang $\mathrm{Wu}^{\mathrm{c}}$ \\ a South China Botanical Garden, Chinese Academy of Sciences, Guangzhou 510650, China \\ ${ }^{\mathrm{b}}$ Graduate School of the Chinese Academy of Sciences, Beijing 100039, China \\ 'Institute of Plant Biology, National Taiwan University, Taipei 106, Taiwan
}

Received 14 March 2008; received in revised form 19 May 2008; accepted 19 May 2008

\section{KEYWORDS \\ Gene expression; \\ High hydrostatic \\ pressure; \\ Rice; \\ Suppression \\ subtractive \\ hybridization}

\begin{abstract}
Summary
High hydrostatic pressure (HHP) is an extreme thermal-physical stress affecting multiple cellular activities. Recently, we found that HHP treatment caused various physiological changes in rice. To investigate the molecular mechanisms of plant response to HHP, we constructed forward and reverse subtracted CDNA libraries of rice seeds treated with $75 \mathrm{MPa}$ hydrostatic pressure for $12 \mathrm{~h}$ by suppression subtractive hybridization in combination with mirror orientation selection. Of 97 clones isolated through microarray dot-blot and sequenced, 45 were unique genes. Among these 45 unique CDNAs, 29 clones showed significant sequence similarity to known genes, 12 were homologous to genes with unknown function, and the remaining 4 clones did not match any known sequences. Most of the genes with known function were involved in metabolism, defense response, transcriptional regulation, transportation regulation, and signal transduction. To our knowledge, this is the first gene expression analysis of rice in response to HHP. The expression profiles of the genes identified in this study provide useful information regarding molecular processes, including alteration of metabolism and adaptation response caused by HHP.

(c) 2008 Elsevier GmbH. All rights reserved.
\end{abstract}

Abbreviations: DIG, digoxigenin; EST, esterase; HHP, high hydrostatic pressure; HSPs, heat shock proteins; MOS, mirror orientation selection; RT-PCR, reverse transcription-polymerase chain reaction; SSH, suppression subtractive hybridization.

*Corresponding author. Tel.: +8620 37252990; fax: +862037252978

E-mail addresses: Ixc06981@163.com (X. Liu), duanj@scib.ac.cn (J. Duan).

${ }^{1}$ These authors contributed equally to this work.

\section{Introduction}

High hydrostatic pressure (HHP) can exert manifold effects on cells and microorganisms, leading to adaptation, stress response, cell death, and growth inhibition (Abe, 2004; Vogel et al., 2005). Pressures greater than $200 \mathrm{MPa}$ can kill most microorganisms 
(Abe, 2007). For examples, Lactobacillus viridescens is killed by $300 \mathrm{MPa}$ exposure and $550 \mathrm{MPa}$ is lethal to Escherichia coli (Sonoike et al., 1993). On the other hand, in many mesophilic microorganisms, cell growth is retarded by hydrostatic pressure in the range of several dozen $\mathrm{MPa}$ and is completely inhibited at about $50 \mathrm{MPa}$ (Bartlett, 2002).

Under high-pressure conditions, some microorganisms can rapidly adjust their genomic expression programs to resist and adapt to the stress. For example, in $E$. coli, genes belonging to the heat shock regulon can be increasingly produced subsequent to a sublethal HHP stress of $150 \mathrm{MPa}$ (Abram et al., 2004), and 11 heat shock proteins (HSPs) are induced after exposure to $55.3 \mathrm{MPa}$ (Welch et al., 1993), indicating a role for HSPs in protection against the damage from HHP. Also, in Saccharomyces cerevisiae, factors for protein degradation such as ubiquitins are induced after HHP treatment, which can eliminate the damaged proteins in organelles and adjust metabolism in response to the stress (Iwahashi et al., 2005). Furthermore, many genes involved in defense response and membrane metabolism in microorganisms are up-regulated after exposure to HHP (Fernandes et al., 2004; Iwahashi et al., 2005). The transcriptional alterations of these genes responding to high pressure may be helpful to survival and growth of the microorganism. However, the effect of HHP on higher plants is still unclear.

Recently, we initiated to study the effect of HHP on rice. We found that the germination of rice seeds was retarded and the growth of seedlings was restrained at the early seedling stage; in addition, expression of esterase (EST) was suppressed (Bai et al., 2003), and activities of $\alpha$-amylase and $\beta$-amylase decreased in germinating seeds (Yan et al., 2007) after treating seeds with HHP. However, the growth of some HHP-treated rice seedlings could exceed that of the control after sowing of $35 \mathrm{~d}$, and the biomass and grain yield of some HHP-treated materials were higher than that of the control when the rice plants were harvested (Li et al., 2003). These changes caused by HHP treatment suggested that HHP might induce adaptive responses in rice seeds and ultimately improve the growth of rice plants. According to these results, we hypothesized that the HHP treatment can adjust gene expression programs in rice seeds in response to the stress. To further investigate, genome-wide transcriptome analyses were employed to gain insight into the global cellular responses to HHP in rice seeds. Genes differentially expressed in germinating rice embryos treated with or without HHP were identified by suppression subtractive hybridization (SSH) in combination with mirror orientation selection (MOS). To our knowledge, this is the first gene expression analysis of rice in response to HHP. Our analysis identified genes involved in metabolism, stress response, transcription regulation, and other signal transduction processes, indicating that rice seeds can adjust gene expression patterns to adapt to HHP stress.

\section{Materials and methods}

\section{Plant material}

Seeds of rice (Oryza sativa ssp. indica cv. Yuefengzhan), provided by Guangdong Academy of Agricultural Sciences, Guangzhou, China, were used for this study.

\section{Hydrostatic pressurization}

The rice seeds (soaked in distilled water at room temperature for $12 \mathrm{~h}$ ) were subjected to continuous $\mathrm{HHP}(75 \mathrm{MPa}, 12 \mathrm{~h}$ at room temperature) as reported (Fernandes et al., 2004). Under $75 \mathrm{MPa}$ HHP, the germination rate of rice seeds was about $50 \%$. The embryos were separated immediately after treatment to isolate mRNA.

\section{mRNA isolation and cDNA synthesis}

Total embryo RNA was isolated with Plant RNAout reagents (Tiandz). Poly $(A)+R N A$ was isolated from total RNA using the FastTrack ${ }^{\circledR}$ MAG mRNA Isolation Kits (Invitrogen). Total mRNA ( $200 \mathrm{ng}$ ) was reverse transcribed to CDNA by using the SMART ${ }^{\mathrm{TM}}$ polymerase chain reaction (PCR) CDNA Synthesis Kit (Clontech) following the manufacturer's instructions. The cDNA from the rice seeds treated by HHP was used as the "tester" cDNA pool and the cDNA from untreated rice seeds was used as the "driver" cDNA pool in the forward SSH experiment to isolate the HHP-induced genes, the reverse SSH experiment was performed with interchange of "driver" and "tester" to isolate the HHP-decreased genes.

\section{Suppression subtractive hybridization (SSH)}

SSH was performed with the PCR Select cDNA Subtraction Kit (Clontech) according to the manufacturer's instructions. MOS was performed as described by Rebrikov et al. (2000). The product of MOS was cloned into pGEM-T easy vector (Promega) and transformed into E. coli JM109 competent cells for differential screening.

To ensure the accuracy of the SSH assay, we analyzed the efficiency of ligation to verify that at least $25 \%$ of the tester CDNA fragments had adaptors on both ends. We also chose the housekeeping gene, actin (Accession number: X15863), as a negative control to estimate the efficiency of subtraction. The actin primers used 
were: forward, 5'-CGTGACCTTACCGACAACCT-3'; reverse, 5'-GCACCTGAACCTTTCTGCTC-3'.

\section{cDNA microarray as a form of reverse RNA gel blot analysis}

A total of 1160 randomly selected clones were further analyzed by dot-blot analysis. Randomly selected clones were cultured overnight in $1 \mathrm{~mL}$ of Luria-Bertani broth containing ampicillin. We used $1 \mu \mathrm{L}$ of the culture for PCR with the primer NP2Rs (5'-GGTCGCGGCCGAGGT-3') in a total volume of $20 \mu \mathrm{L}$ reaction mixture. Of PCR products, $0.4 \mu \mathrm{L}$ was spotted on Zeta-Probe GT membranes (BioRad) in a $0.25 \mathrm{~cm}^{2}$ portion. The membrane with DNA was placed on a wet filter paper rinsed with $0.4 \mathrm{M} \mathrm{NaOH}$ for $5 \mathrm{~min}$ to denature the DNA, then immediately briefly rinsed in $2 \times$ saline-sodium citrate buffer to wash the redundant alkali solution. After crosslinking in a baker at $80^{\circ} \mathrm{C}$ for $2 \mathrm{~h}$, the membrane was hybridized with a specific probe or conserved at room temperature for future use.

Digoxigenin (DIG)-labeled DNA probes were generated and signals were detected by a DIG High Prime DNA Labeling and Detection Starter Kit II (Roche) following the manufacturer's instruction. To further eliminate falsepositive clones, we chose four cDNAs as templates to prepare probes for hybridization. Screening was conducted as described previously (Diatchenko et al., 1999). Putative differential clones were selected for DNA sequencing.

\section{Sequence analysis and blast search}

Plasmid DNA was used as a template for automated sequencing with an $A B I$ PRISM dye terminator cycle sequencing kit and $\mathrm{ABI}$ Model 377 DNA sequencer (Perkin-Elmer). The M13 reverse universal primer was used to sequence DNA templates. CDNA identities were determined by sequence comparison with the GenBank database (http://www.ncbi.nlm.nih.gov/) and KOME database (www.cdna01.dna.affrc.go.jp/cDNA/) using blastn or BLASTX. Classification of annotated sequences was searched by Gene Ontology (http://www. godatabase.org).

\section{Semi-quantitative RT-PCR}

Total RNA was extracted with Plant RNAout (Tiandz) reagent as in the instruction manual. RNA was treated with the DNasel (Takara) and then used for the synthesis of first-strand CDNA using an oligo-dT primer. First-strand CDNA synthesis was performed with $1 \mu \mathrm{g}$ total RNA using an M-MLV reverse transcriptase (Promega), and the products were standardized for semi-quantitative reverse transcription-polymerase chain reaction (RT-PCR) using actin (Accession number: X15863) as a control. Specific oligonucleotides were designed for each chosen CDNA using Primer Premier 5 (Premier Biosoft International) and used in sets for PCR (Table 1). The PCR reactions were performed as 30 or 33 cycles at $94^{\circ} \mathrm{C}$ for
$30 \mathrm{~s}, 57^{\circ} \mathrm{C}$ for $30 \mathrm{~s}$, and $72{ }^{\circ} \mathrm{C}$ for $45 \mathrm{~s}$. Each reaction was repeated at least once with another batch of CDNA. After separation on $1 \%(\mathrm{w} / \mathrm{v})$ agarose gels, the intensities of the same DNA products were compared between reactions from different templates.

\section{Results}

\section{Construction and differential screening of subtractive libraries}

SSH provides a powerful method to analyze global expression profiles. To identify specific gene expression of the rice seeds in response to HHP at the transcriptional level, SSH was employed and two subtracted CDNA libraries constructed. In the forward subtracted library, tester CDNA was from HHP-treated rice seeds whereas the reverse subtracted library was from the control.

The efficiency of the SSH procedure was assessed by depletion of the housekeeping gene actin and determined by PCR amplification over a graded increase in the number of cycles. The actin was visible after 28 cycles (Figure 1, lane 3) in the forward subtracted CDNA libraries, whereas it was clearly detected in the forward unsubtracted samples after only 18 cycles (lane 5 ). In the reverse subtraction, the actin band was detectable after 33 cycles, which was 10 cycles more than the unsubtracted. Both forward and reverse subtracted cDNA libraries had high subtraction efficiency.

Of the cDNA clones, 580 forward subtracted and 580 reverse subtracted were randomly selected and the inserts re-amplified by PCR. The lengths of PCR products were $0.2-1.8 \mathrm{~kb}$. The cDNAs were dotblotted on membrane and hybridized with four kinds of DIG-labeled probes (Figure 2). As a result, 97 clones (63 forward subtracted and 34 reverse subtracted clones) that showed a strong positive signal on reverse dot-blot analysis were selected, and all the positive clones were sequenced.

\section{Identification of differentially expressed genes}

After comparisons with the GenBank database by BLASTN or BLASTX search, 45 sequences were identified as unique genes and the other 52 sequences as repeated clones. These genes are summarized in Tables 2 and 3 and Figure 3.

Among the forward subtracted genes (Table 2, up-regulated genes), 17 sequences had sequence similarity to genes with known functions, 11 sequences were similar to genes of unknown 
Table 1. Sequences of primer pairs for RT-PCR

\begin{tabular}{|c|c|c|c|c|}
\hline Clone & Identity & $\begin{array}{l}\text { Primer sequence (forward and } \\
\text { reverse } 5^{\prime}-3^{\prime} \text { ) }\end{array}$ & $\begin{array}{l}\text { Annealing } \\
\text { temperature }\left({ }^{\circ} \mathrm{C}\right)\end{array}$ & $\begin{array}{l}\text { Product } \\
\text { size (bp) }\end{array}$ \\
\hline $\mathrm{H9}$ & Glyoxalase I & $\begin{array}{l}\text { GTCTCCACTCCACTGAATCC } \\
\text { AATTCCAGTGCAAAGTTGGT }\end{array}$ & 57 & 276 \\
\hline $\mathrm{H} 97$ & $\begin{array}{l}\text { Arginine/serine rich splicing } \\
\text { factor } 1\end{array}$ & $\begin{array}{l}\text { TCACGCTCATCCTCAAAGTA } \\
\text { CTTGCTGTCTTGGGATCTTT }\end{array}$ & 57 & 186 \\
\hline $\mathrm{H} 102$ & $\mathrm{Cu} / \mathrm{Zn}$-superoxide dismutase & $\begin{array}{l}\text { TGTCAACTGGACCACACTTC } \\
\text { ACTTAAAACGCATGCACTCA }\end{array}$ & 57 & 462 \\
\hline $\mathrm{H} 105$ & Glycine rich protein & $\begin{array}{l}\text { TGGTGGTTATGCTCAAGCTG } \\
\text { GGTCCTCAGTGTGGTTCGAT }\end{array}$ & 58 & 355 \\
\hline $\mathrm{H} 145$ & TA4 protein & $\begin{array}{l}\text { ATTGTGTCGCAAGATCCATT } \\
\text { GGGGGCAAATTCAAGTTTAT }\end{array}$ & 57 & 445 \\
\hline $\mathrm{H} 284$ & ADP-ribosylation factor & $\begin{array}{l}\text { TGGTGGTCAGGACAAGATCA } \\
\text { CTTGTTGGCAATGTTGTTGG }\end{array}$ & 58 & 337 \\
\hline H532 & $\begin{array}{l}\text { Cell death-related protein } \\
\text { SPL11 }\end{array}$ & $\begin{array}{l}\text { TTGGAGGAATTAGCCAAAAG } \\
\text { GCTTATCAACCGTCTCGTCT }\end{array}$ & 57 & 260 \\
\hline H545 & Heat shock protein 90 & $\begin{array}{l}\text { TCATGGACAACTGTGAGGAG } \\
\text { ATCACCACTCTTGGTGGAGT }\end{array}$ & 57 & 308 \\
\hline CK43 & Retrotransposon & $\begin{array}{l}\text { GCTGCATACCGACAGGAAGT } \\
\text { TCCGCTTGGTITCGTCTTTA }\end{array}$ & 58 & 359 \\
\hline CK354 & $\begin{array}{l}\text { Peroxisomal multifunctional } \\
\text { protein }\end{array}$ & $\begin{array}{l}\text { TGCCTTTGGAACAAGGAATC } \\
\text { CCATCCCAAGGATAGAAGCA }\end{array}$ & 58 & 320 \\
\hline CK361 & $\begin{array}{l}15 \mathrm{kDa} \text { organ-specific salt- } \\
\text { induced protein }\end{array}$ & $\begin{array}{l}\text { GCTTCTAGGCGTGACAATCT } \\
\text { CAGAGTCTTGCAGTGGAATG }\end{array}$ & 57 & 293 \\
\hline CK370 & 33-kDa secretory protein & $\begin{array}{l}\text { TCTTATCAATGCACGGTGAC } \\
\text { TTCGTGAGTGTCTACGCATT }\end{array}$ & 57 & 245 \\
\hline CK423 & Thionin Osthi 1 & $\begin{array}{l}\text { GCTAGGCTTAGTCCTGCAAC } \\
\text { GGTGACAGTCTCAGCTTCCT }\end{array}$ & 57 & 399 \\
\hline CK449 & Alcohol dehydrogenase 1 & $\begin{array}{l}\text { ACATGAAGAAGGAGCTGGAG } \\
\text { GAAATTTGCCCAGGATACAC }\end{array}$ & 57 & 265 \\
\hline CK450 & $\begin{array}{l}\text { OVP3 gene for vacuolar } \\
\text { proton pyrophosphatase }\end{array}$ & $\begin{array}{l}\text { CGGAGGAATTCTATTCAAGC } \\
\text { TCAGGCAGACAGAAACTGAA }\end{array}$ & 57 & 246 \\
\hline CK522 & Pyruvate decarboxylase 1 & $\begin{array}{l}\text { CAGACGATGATAAGCAGCAC } \\
\text { CAAGAAAGACTGCCTCTGCT }\end{array}$ & 57 & 278 \\
\hline
\end{tabular}

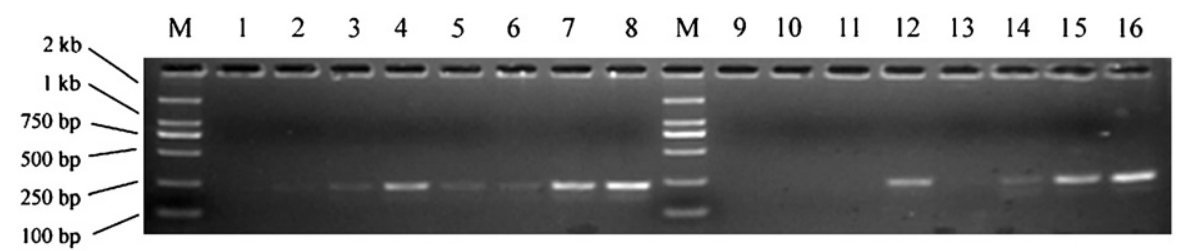

Figure 1. SSH subtraction efficiency analysis. Subtraction efficiency was determined by analyzing the amount of actin present in both the subtracted cDNA and the unsubtracted cDNA through the use of increasing numbers of PCR cycles (for 18, 23, 28 or 33 cycles). Lane M, DL 2000 marker; Lane 1-4, lane 5-8, lane 9-12, and lane 13-16 were forward subtracted samples, forward unsubtracted samples, reverse subtracted samples, and reverse unsubtracted samples, respectively. 


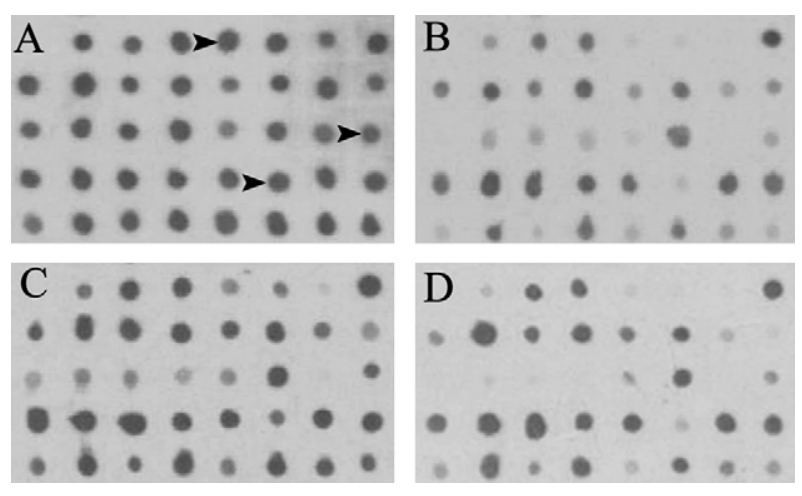

Figure 2. Typical results of reverse dot-blot analyses. Four identical membranes were hybridized with DIGlabeled probes prepared from (A) forward subtracted cDNA, (B) reverse subtracted cDNA, (C) forward unsubtracted $C D N A$ and $(D)$ reverse unsubtracted cDNA. Several differentially expressed clones are marked with arrows.

function, and 2 sequences were novel genes that had no significant similarity to any identified genes in the GenBank database. The cellular roles of the genes identified by forward subtraction were classified into metabolism (including carbohydrate metabolism, protein storage, and biosynthesis), defense response (response to oxidation, protein ubiquitination) and transcriptional regulation.

Among the reverse subtracted clones (Table 3, down-regulated genes), 12 sequences showed similarity to genes with known functions, 1 sequence was similar to a gene with unknown function and 2 sequences were novel genes. The cellular functions of these genes with known function identified by reverse subtraction can be classified into metabolism (including protein storage and biosynthesis), defense response (response to hypoxia, disease, and stress), transcription regulation, signal transduction, development, and nucleotide binding.

\section{Expression pattern of candidate pressure response gene}

To further verify and validate the results obtained by SSH, eight up- and eight downregulated genes that showed a positive signal on reverse dot-blot analysis were randomly selected for semi-quantitative RT-PCR. The relative abundances were determined utilizing housekeeping gene actin as an internal control. The RT-PCR results of 16 genes are shown in Figure 4 . The expression levels of the eight up-regulated genes were obviously higher than the control, whereas expression levels of the down-regulated genes were significantly lower than control, indicating that the expression profiles of up- and down-regulated genes were in accord with the result of reverse dot-blotting. Overall, the expression patterns from RT-PCR reflected the SSH results, demonstrating a low false-positive rate associated with SSH in this experiment.

\section{Discussion}

HHP is an extreme thermal-physical stress affecting multiple cellular activities, including chromosome structure (Zhang and Onozato, 2004), membrane integrity (Ritz et al., 2002), DNA-protein interaction (Lynch and Sligar, 2002), and gene expression (Fernandes et al., 2004; Iwahashi et al., 2005). Recently, we found that HHP treatment caused various physiological changes in rice (Bai et al., 2003; Li et al., 2003; Yan et al., 2007). To investigate the molecular mechanisms involved, we examined the gene expression profiles of germinating rice seeds in response to $75 \mathrm{MPa}$ HHP using SSH. The expression profiles provide a good starting point for understanding the molecular effects in rice seeds responding to HHP.

We identified 45 unique genes, including up- and down-regulated genes. Most of these genes can be classified into different functional categories including metabolism, defense response, transcriptional regulation, transportation regulation, and signal transduction. Of these genes, 12 encode proteins with unknown function and 4 are novel genes. Among those with known function (Figure 3), 21 genes (46.7\% of total) are involved in metabolism and defense response, which could provide information on physiological responses during HHP. Moreover, genes involved in other physiological processes are also useful for understanding the molecular processes in rice during HHP treatment.

\section{Genes involved in metabolism were affected by HHP}

Genes involved in carbohydrate metabolism and biosynthesis were up-regulated after HHP treatment. S-adenosylmethionine decarboxylase is one of the most important common enzymes in polyamine biosynthesis for production of spermidine and spermine from putrescine (Roy and Wu, 2002). Previous studies found that spermidine and spermine play an important role in enhancing rice resistance to abiotic stress ( $\mathrm{Li}$ and Chen, 2000). $S$-adenosylmethionine decarboxylase was also reported to be involved in salt and drought stress 
Table 2. Up-regulated genes

\begin{tabular}{|c|c|c|c|c|c|}
\hline Clone & $\begin{array}{l}\text { Length } \\
\text { (bp) }\end{array}$ & $\begin{array}{l}\text { Accession } \\
\text { number }\end{array}$ & Homology & E-value & $\begin{array}{l}\text { Location in } \\
\text { chromosome }\end{array}$ \\
\hline \multicolumn{6}{|c|}{ Metabolism (carbohydrate metabolism, protein storage and biosynthesis) } \\
\hline $\mathrm{H} 47$ & 530 & X05662 & Glutelin type I & 0.0 & 1 \\
\hline $\mathrm{H} 120$ & 501 & AB016501 & Glutelin & 0.0 & 2 \\
\hline H139 & 509 & AJ251899 & S-adenosylmethionine decarboxylase 2 & 0.0 & 2 \\
\hline H149 & 920 & AAR13692 & $\mathrm{Fe}^{2+}$ dioxygenase-like protein & $1 e-66$ & 4 \\
\hline H388 & 340 & AF156714 & Prolamin (RP5) gene & 0.0 & 7 \\
\hline $\mathrm{H} 416$ & 470 & AF194115 & Prolamin 7 gene & 0.0 & 5 \\
\hline \multicolumn{6}{|c|}{ Defense response (response to oxidation, protein ubiquitination) } \\
\hline $\mathrm{H9}$ & 456 & AK103694 & Glyoxalase I & $1 e-170$ & 8 \\
\hline $\mathrm{H} 102$ & 728 & D01000 & Copper/zinc-superoxide dismutase & 0.0 & 7 \\
\hline $\mathrm{H} 105$ & 434 & AB059239 & Glycine rich protein & 0.0 & 10 \\
\hline H342 & 324 & AF198626 & Copper chaperone $(\mathrm{CCH})$ & $7 e-27$ & 8 \\
\hline H407 & 278 & AAU14999 & MtN19-like protein & $5 e-36$ & 8 \\
\hline H513 & 951 & AF184280 & polyubiquitin (RUBQ2) gene & 0.0 & 2 \\
\hline H532 & 741 & AK121978 & Cell death-related protein SPL11 & 0.0 & 3 \\
\hline H545 & 500 & AK101323 & Heat shock protein 90 (HSP90) & 0.0 & 9 \\
\hline \multicolumn{6}{|c|}{ Transcriptional regulation } \\
\hline H97 & 934 & AK102071 & Arginine/serine-rich splicing factor 1 & 0.0 & 4 \\
\hline $\mathrm{H} 145$ & 936 & AJ575228 & TA4 protein & 0.0 & 2 \\
\hline $\mathrm{H} 284$ & 284 & AK067029 & ADP-ribosylation factor & $1 e-144$ & 5 \\
\hline \multicolumn{6}{|c|}{ Unknown protein } \\
\hline $\mathrm{H} 128$ & 332 & ABF95824 & & $3 e-55$ & 3 \\
\hline $\mathrm{H} 232$ & 328 & AK072775 & & $2 e-149$ & 12 \\
\hline $\mathrm{H} 274$ & 556 & AK066751 & & 0.0 & 12 \\
\hline H334 & 496 & AK240743 & & 0.0 & 11 \\
\hline H335 & 341 & AP008214 & & $6 e-117$ & 8 \\
\hline H370 & 1150 & AAV44205 & & $8 e-33$ & 5 \\
\hline H394 & 496 & AK122111 & & $1 e-127$ & 12 \\
\hline $\mathrm{H} 467$ & 521 & AK073700 & & $2 e-165$ & 4 \\
\hline $\mathrm{H} 469$ & 802 & AK066751 & & 0.0 & 12 \\
\hline H473 & 591 & AK067080 & & 0.0 & 11 \\
\hline $\mathrm{H} 490$ & 662 & AK067980 & & 0.0 & 5 \\
\hline \multicolumn{6}{|c|}{ Novel gene } \\
\hline $\mathrm{H} 259$ & 335 & & & & \\
\hline H557 & 254 & & & & \\
\hline
\end{tabular}

responses (Roy and Wu, 2001). The increased expression of S-adenosylmethionine decarboxylase 2 may be an adaptive reaction of rice seeds to HHP. In addition, HHP induced the expression of $\mathrm{Fe}^{2+}$ dioxygenase-like protein, but suppressed the expression of cinnamoyl CoA reductase. The functional significance of these changes remains to be investigated.

\section{HHP changed the expression of genes involved in stress response}

HHP is an extreme condition, which may cause intensive stress to rice seeds and even cell death. In this study, we found that eight genes involved in defense response were up-regulated under HHP treatment, including those genes encoding glyoxalase I, Cu/Zn superoxide dismutase (Cu/Zn SOD), copper chaperone $(\mathrm{CCH})$, glycine-rich protein, MtN19-like protein, heat shock protein 90 (HSP90), polyubiquitin, and cell-death-related protein.

Glyoxalase I is a key enzyme of the glyoxalase pathway, which plays an important role in the detoxification of methylglyoxal formed due to several abiotic stresses (Bowler et al., 1992). Over-expression of glyoxalase-pathway-related genes in transgenic tobacco enhances heavy metal tolerance (Veena et al., 1999). Up-regulation of glyoxalase suggests that it may play an important role in protection of cells from high-pressure stress. 
Table 3. Down-regulated genes

\begin{tabular}{|c|c|c|c|c|c|}
\hline Clone & $\begin{array}{l}\text { Length } \\
\text { (bp) }\end{array}$ & $\begin{array}{l}\text { Accession } \\
\text { number }\end{array}$ & Homology & $E$-value & $\begin{array}{l}\text { Location in } \\
\text { chromosome }\end{array}$ \\
\hline \multicolumn{6}{|c|}{ Metabolism (protein storage, biosynthesis) } \\
\hline CK303 & 651 & X05664 & Glutelin type II & 0.0 & 2 \\
\hline Ck422 & 289 & AJ428493 & ccr gene for cinnamoyl CoA reductase & $2 e-27$ & 2 \\
\hline \multicolumn{6}{|c|}{ Defense response (response to hypoxia, disease and stress) } \\
\hline CK449 & 271 & X16296 & Alcohol dehydrogenase 1 (adh1) & $9 e-132$ & 11 \\
\hline CK522 & 285 & U07339 & Pyruvate decarboxylase 1 (pdc1) & $3 e-141$ & 5 \\
\hline CK379 & 359 & AF274850 & Pathogenesis-related protein PR-10a & $3 e-178$ & 12 \\
\hline CK361 & 461 & S45168 & $15 \mathrm{kDa}$ organ-specific salt-induced protein & 0.0 & 1 \\
\hline CK423 & 510 & AB072337 & Thionin Osthi1 & 0.0 & 6 \\
\hline \multicolumn{6}{|c|}{ Transportation } \\
\hline CK450 & 313 & AB126350 & $\begin{array}{l}\text { OVP3 gene for vacuolar proton } \\
\text { pyrophosphatase }\end{array}$ & $2 e-158$ & 2 \\
\hline \multicolumn{6}{|c|}{ Signal transduction } \\
\hline CK413 & 416 & BAC79540 & Putative serine/threonine kinase & $4 e-77$ & 7 \\
\hline \multicolumn{6}{|c|}{ Development } \\
\hline CK354 & 605 & AF442962 & Peroxisomal multifunctional protein & 0.0 & 2 \\
\hline \multicolumn{6}{|c|}{ Nucleotide binding } \\
\hline CK43 & 357 & ABB46597 & Retrotransposon & $8 e-09$ & 1 \\
\hline CK370 & 392 & AF311908 & $33-\mathrm{kDa}$ secretory protein & 0.0 & 8 \\
\hline \multicolumn{6}{|c|}{ Unknown protein } \\
\hline CK312 & 670 & AK066268 & & 0.0 & 5 \\
\hline \multicolumn{6}{|c|}{ Novel gene } \\
\hline CK202 & 675 & & & & \\
\hline CK366 & 339 & & & & \\
\hline
\end{tabular}

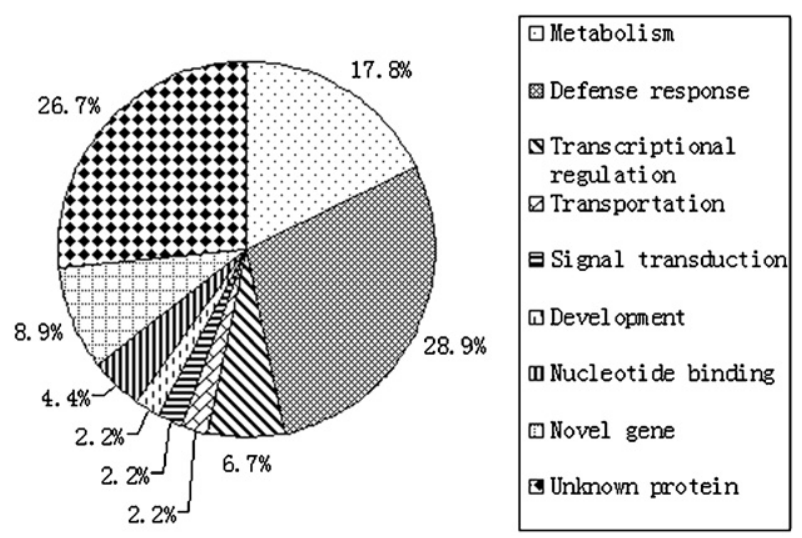

Figure 3. Functional classes of genes identified from forward and reverse subtracted CDNA libraries. Clones were classified into 9 unique categories. Percentages represent the proportions of genes belonging to a particular functional group of the total number of genes, including genes with known functions, unknown functions and novel sequences.

$\mathrm{Cu} / \mathrm{Zn}$ SOD belongs to a family of metalloenzymes which catalyze the conversion of superoxide anion $\left(\mathrm{O}^{2-}\right)$ radicals to molecular oxygen and hydrogen peroxide $\left(\mathrm{H}_{2} \mathrm{O}_{2}\right)$. The function of this protein is to remove oxygen free radicals and protect the organism from oxidative damage. High SOD activity has been associated with stress tolerance in plants because it neutralizes the reactivity of $\mathrm{O}^{2-}$, which is overproduced under oxidative stress (Ahsan et al., 2007). The increased expression of $\mathrm{Cu} / \mathrm{Zn}$ SOD may also be an adaptive reaction of rice seeds to resist oxidative stress when exposed to HHP. The up-regulated $\mathrm{CCH}$ may act as a molecular chaperone specifically delivering copper to the $\mathrm{Cu} / \mathrm{Zn}$ SOD to resist the damage caused by $\mathrm{O}^{2-}$.

HSPs can play a crucial role in protecting plants against stress by reestablishing normal protein conformation and thus cellular homeostasis (Wang et al., 2004). The increased expression of HSP90 is helpful to maintain activity of proteins in rice seeds when exposed to HHP.

\section{HHP-induced gene expression involved in transcriptional regulation}

Transcription factors play key roles in gene regulation during various developmental stages 


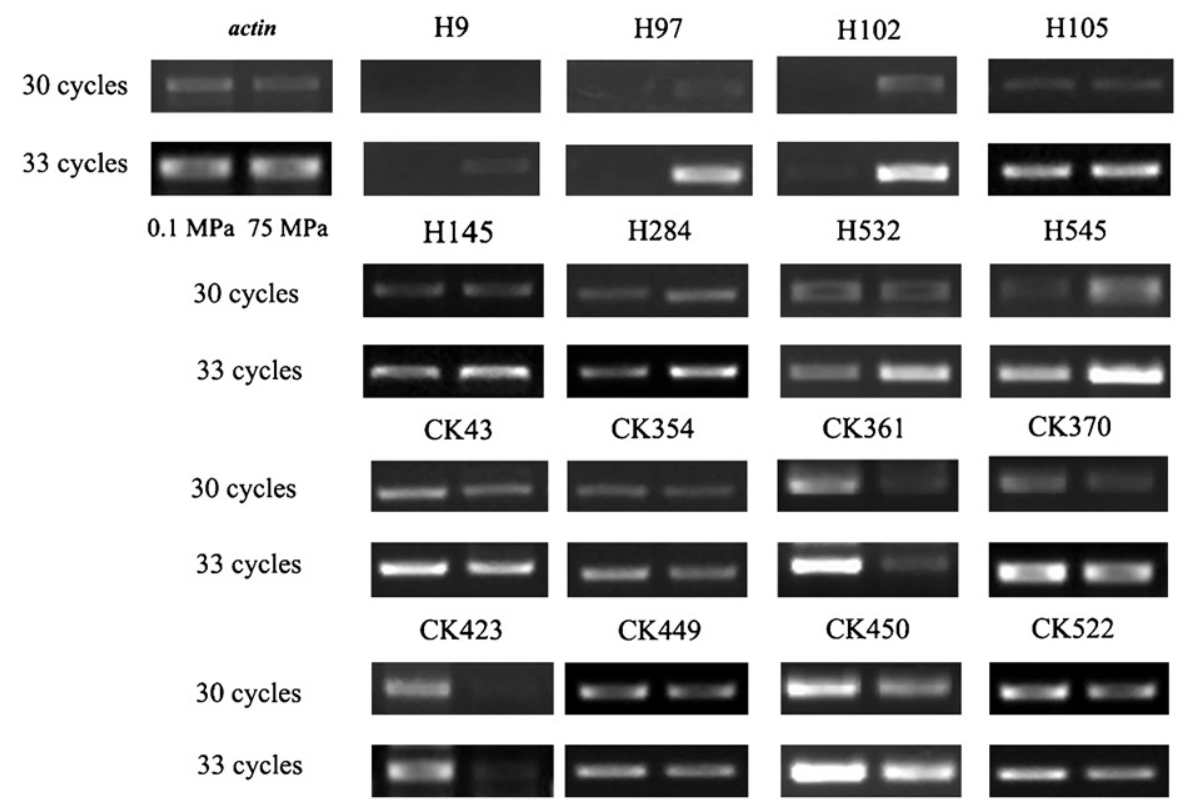

Figure 4. Comparison of 16 differentially expressed genes between control ( $0.1 \mathrm{MPa})$ and $\mathrm{HHP}(75 \mathrm{MPa})$ treatment using semi-quantitative RT-PCR. H9 (glyoxalase I), H97 (arginine/serine-rich splicing factor 1), H102 (Cu/Zn-superoxide dismutase), H105 (glycine-rich protein), H145 (TA4 protein), H284 (ADP-ribosylation factor), H532 (cell-death-related protein SPL11), and H545 (heat shock protein 90) were up-regulated genes. CK43 (retrotransposon), CK354 (peroxisomal multifunctional protein), CK361 (15 kDa organ-specific salt-induced protein), CK370 (33-kDa secretory protein), CK423 (thionin Osthi 1), CK449 (alcohol dehydrogenase 1), CK450 (OVP3 gene for vacuolar proton pyrophosphatase), and CK522 (pyruvate decarboxylase 1) were down-regulated genes. For each sample, 30 and 33 PCR cycles were performed separately.

and cellular responses to environmental factors (Ye et al., 2004). In this study, we identified three up-regulated ESTs involved in transcription regulation (Table 2). Serine/arginine-rich splicing proteins play important roles in constitutive and alternative splicing as well as other aspects of mRNA metabolism (Ali et al., 2007). The up-regulation of arginine/ serine-rich splicing factor 1 suggests that high pressure could improve the production of mature mRNAs and eventually stimulate the efficiency of transcription. TA4 protein was identified as transcriptional activator during rice embryo development (Ye et al., 2004). The increased expression of TA4 suggests that high pressure may activate gene expression involved in embryo development. ADPribosylation factors (ARFs) are a family of Ras-related GTP-binding proteins (Donaldson and Honda, 2005). Many cellular processes in eukaryotes are regulated by small GTP-binding proteins (Hall, 1998). ARFs are $\mathrm{N}$-terminally myristoylated conserved GTP-binding proteins, which not only function in intracellular vesicle trafficking but also in signal transduction networks. Previous studies demonstrated that ARFs could increase the antioxidant capacity of transgenic potato tubers (Zuk et al., 2003). We found that HHP induced the expression of ARF mRNAs in germinating rice seeds, suggesting that ARFs may play a significant regulatory role in coping with multiple stresses imposed by HHP. Further study is required to verify the physiological functions of these transcription factors.

In addition, genes involved in transportation regulation were also affected by HHP. Vacuolar proton pyrophosphatase $\left(\mathrm{H}^{+}\right.$-PPase) is a membraneassociated protein. It generates an $\mathrm{H}^{+}$-electrochemical potential that motivates secondary transport of ions or metabolites across the vacuole membrane (Maeshima, 2000). It has been reported that salt stress markedly inhibited the activities of tonoplast $\mathrm{H}^{+}$-PPase in cucumber roots (Shi et al., 2007). We found that HHP also suppressed the expression of $\mathrm{H}^{+}$-Ppase, which may result in reduced transportation.

In conclusion, SSH is an effective technique to study gene expression of rice seeds in response to HHP. The expression profiles of the genes identified in this study provide useful information regarding molecular processes, including alteration of metabolism and adaptation responses initiated by HHP treatment. The up-regulation of genes such as S-adenosylmethionine decarboxylase 2, HSP90, glyoxalase I, Cu/Zn SOD and $\mathrm{CCH}$ suggests some adaptive reactions of rice seeds to HHP. We also identified 12 genes encoding proteins of unknown 
function that were up- or down-regulated by HHP. Further analysis of the function of these unknown proteins may provide additional information on HHP effects on rice seeds.

\section{Acknowledgments}

We thank Dr. Wang Xiaolan for her help in SSH assay. This project was financially supported by grants from the Natural National Science Foundation of China (No. 30471002), the Natural Science Foundation of Guangdong Province, China (No. 05103637) and the start-up funds for scientific research of South China Botanic Garden, Chinese Academy of Sciences.

\section{Appendix A. Supplementary materials}

Supplementary data associated with this article can be found in the online version at doi:10.1016/ j.jplph.2008.05.004

\section{References}

Abe F. Piezophysiology of yeast: occurrence and significance. Cell Mol Biol 2004;50:437-45.

Abe F. Exploration of the effects of high hydrostatic pressure on microbial growth, physiology and survival: perspectives from piezophysiology. Biosci Biotechnol Biochem 2007;71:2347-57.

Abram A, Kristof V, Philipp DS. Heat shock proteinmediated resistance to high hydrostatic pressure in Escherichia coli. Appl Environ Microbiol 2004;70: 2660-6.

Ahsan N, Lee DG, Lee SH, Kang KY, Lee JJ, Kim PJ, et al. Excess copper induced physiological and proteomic changes in germinating rice seeds. Chemosphere 2007; 67:1182-93.

Ali GS, Palusa SG, Golovkin M, Prasad J, Manley JL, Reddy ASN. Regulation of plant developmental processes by a novel splicing factor. PLOS ONE 2007;2:e471.

Bai CK, Li GS, Duan J, Peng CL, Duan ZG, Weng KN, et al. Effect of high hydrostatic pressure on seeds germination and seedling isoenzyme in rice (Oryza sativa L.). Chin J High Press Phys 2003;17:283-9.

Bartlett DH. Pressure effects on in vivo microbial processes. Biochim Biophys Acta 2002;1595:367-81.

Bowler C, Montagu MV, Inze D. Superoxide dismutase and stress tolerance. Annu Rev Plant Physiol Plant Mol Biol 1992;43:83-116.

Diatchenko L, Lukyanov S, Lau YF, Siebert PD. Suppression subtractive hybridization: a versatile method for identifying differentially expressed genes. Methods Enzymol 1999;303:349-80.

Donaldson JG, Honda A. Localization and function of Arf family GTPases. Biochem Soc Trans 2005;33:639-42.
Fernandes PMB, Domitrovic T, Kao CM, Kurtenbach E. Genomic expression pattern in Saccharomyces cerevisiae cells in response to high hydrostatic pressure. FEBS Lett 2004;556:153-60.

Hall A. G proteins and small GTPases: distant relatives keep in touch. Science 1998;280:2074-5.

Iwahashi H, Odani M, Ishidou E, Kitagawa E. Adaptation of Saccharomyces cerevisiae to high hydrostatic pressure causing growth inhibition. FEBS Lett 2005; 579:2847-52.

Li ZY, Chen SY. Differential accumulation of S-adenosylmethionine decarboxylase transcript in rice seedlings in response to salt and drought stresses. Theor Appl Genet 2000;100:782-8.

Li GS, Bai CK, Duan J, Peng CL, Weng KN, Liu SD. Effect of high hydrostatic pressure treatment on physiological characteristics of rice plants (Oryza sativa L.). Chin J High Press Phys 2003;17:122-8.

Lynch TW, Sligar SG. Experimental and theoretical high pressure strategies for investigating protein-nucleic acid assemblies. Biochim Biophys Acta 2002;1595: 277-82.

Maeshima M. Vacuolar $\mathrm{H}^{+}$-pyrophosphatase. Biochim Biophys Acta 2000;1465:37-51.

Rebrikov DV, Britanova OV, Gurskaya NG, Lukyanov KA, Tarabykin VS, Lukyanov SA. Mirror orientation selection (MOS): a method for eliminating false positive clones from libraries generated by suppression subtractive hybridization. Nucleic Acids Res 2000;28: $1-4$.

Ritz M, Tholozan JL, Federighi M, Pilet MF. Physiological damages of Listeria monocytogenes treated by high hydrostatic pressure. Int J Food Microbiol 2002;79: 47-53.

Roy M, Wu R. Arginine decarboxylase transgene expression and analysis of environmental stress tolerance in transgenic rice. Plant Sci 2001;160:869-75.

Roy M, Wu R. Overexpression of $S$-adenosylmethionine decarboxylase gene in rice increases polyamine level and enhances sodium chloride-stress tolerance. Plant Sci 2002;163:987-92.

Shi QH, Ding F, Wang XF, Wei M. Exogenous nitric oxide protect cucumber roots against oxidative stress induced by salt stress. Plant Physiol Biochem 2007; 45:542-50.

Sonoike K, Setoyama T, Kuma Y, Shinno T, Fukumoto K, Ishihara $M$. Effects of pressure and temperature on the death rate of Lactobacillus casei and Escherichia coli. In: Hayashi R, editor. High pressure bioscience in food science. Kyoto: Sanei Press; 1993. p. 213-9.

Veena, Reddy VS, Sopory SK. Glyoxalase I from Brassica juncea: molecular cloning, regulation and its overexpression confer tolerance in transgenic tobacco under stress. Plant J 1999;17:385-95.

Vogel RF, Pavlovic M, Hormann S, Ehrmann MA. High pressure-sensitive gene expression in Lactobacillus sanfranciscensis. Braz J Med Biol Res 2005;38: 1247-52.

Wang WX, Vinocur B, Shoseyov O, Altman A. Role of plant heat-shock proteins and molecular chaperones in 
the abiotic stress response. Trends Plant Sci 2004;9: 244-52.

Welch TJ, Farewell A, Neidhardt FC, Bartlett DH. Stress response of Escherichia coli to elevated hydrostatic pressure. J Bacteriol 1993;175:7170-7.

Yan P, Li GS, Duan J. Effects of high pressure on cell membrane permeability and activity of amylase of rice seeds. J Zhejiang Univ 2007;33:174-9.

Ye R, Yao QH, Xu ZH, Xue HW. Development of an efficient method for the isolation of factor involved in gene transcription during rice embryo development. Plant J 2004;38:348-57.

Zhang $\mathrm{XL}$, Onozato $\mathrm{H}$. Hydrostatic pressure treatment during the first mitosis does not suppress the first cleavage but the second one. Aquaculture 2004;240: 101-13.

Zuk M, Prescha A, Kepczynski J, Szopa J. ADP ribosylation factor regulates metabolism and antioxidant capacity of transgenic potato tubers. J Agric Food Chem 2003; 51:288-94. 